
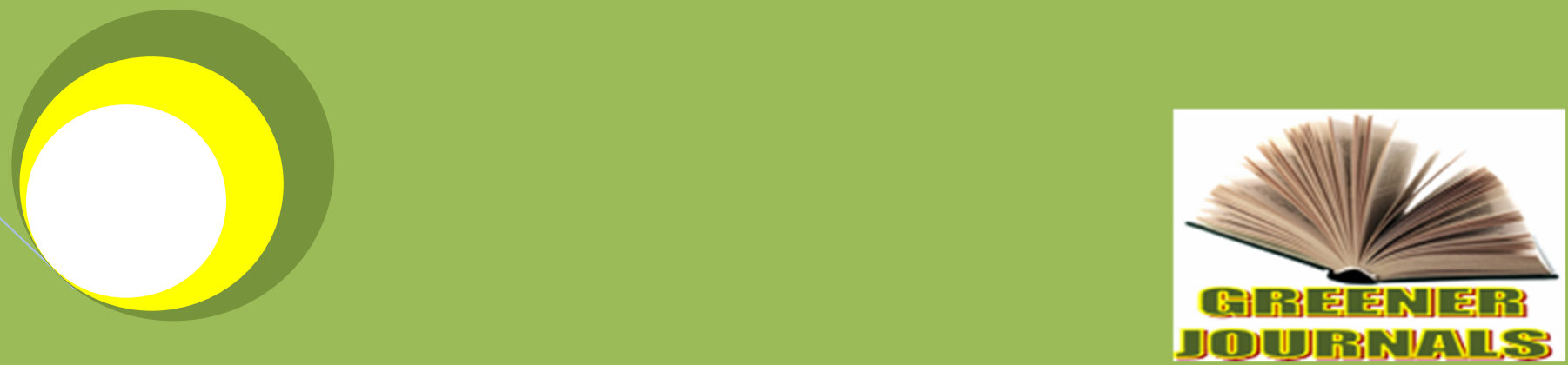

Gieeneris lounnal of Fl lant Breeding and Cronscience

ISSN: 2354-2292

Submitted: 30/08/2016

Accepted: 22/09/2016

Published: 28/03/2017

Subject Area of Article: Plant Breeding

DOI: http://doi.org/10.15580/GJPBCS.2017.1.083016140

Seed Yield Stability and

Genotype × Environment

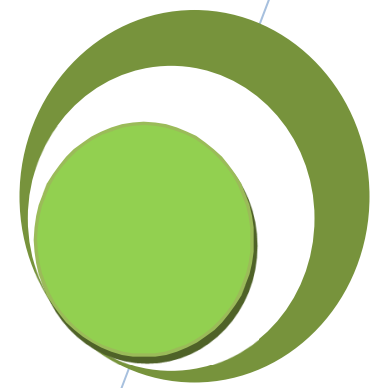

Interaction in Common

Bean (Phaseolus

vulgaris L.) Varieties in

Dawro Zone,

Southwestern Ethiopia

By

Zeleke Ashango Sentayehu Alamerew 


\title{
Seed Yield Stability and Genotype × Environment Interaction in Common Bean (Phaseolus vulgaris L.) Varieties in Dawro Zone, Southwestern Ethiopia
}

\author{
Zeleke Ashango ${ }^{1^{*}}$, Sentayehu Alamerew ${ }^{2}$
}

\author{
${ }^{1}$ Melkassa Agricultural Research Center, Adama, Ethiopia; ${ }^{2}$ Jimma University, College of Agriculture and Veterinary \\ Medicine, Jimma, Ethiopia. \\ *Corresponding Author's E-mail: zelekemarc2014@gmail. com
}

\begin{abstract}
Stable yield performance of genotypes is very important in countries like Ethiopia where means to modify environments are limited. However, happening of significant genotype $X$ environment interaction (GEI) complicates selection of stable genotypes. In Ethiopia, the yield potential of common bean varieties is underutilized due to inadequate addressing of all potential areas and mismatch between selection and production environments. Thus, 14 common bean varieties were evaluated at seven locations for seed yield performance using Randomized complete block design with three replications in the $\mathbf{2 0 1 0}$ main cropping season to estimate the magnitude of GLI effects and to identify broadly or specifically adapted varieties. Combined ANOVA, AMMI and GGE biplot models were used to analyze the data. Both main and interaction effects were highly significant $(P<0.01)$ and location, variety, and GLI explained $50.3 \%, 28.8 \%$ and $20.9 \%$ variations, respectively, indicating greater influence of location and importance of simultaneous consideration of mean performance and GLI (stability). PC1 and PC2 were highly significant $(p<0.01)$ and together contributed more than $79 \%$ variation in the GLI sum of squares. AMMI 1 biplot enabled identification of both high seed yielding and broadly adapted Varieties, Zebra-90, Goberasha, Roba-1, Nasir, and Omo-95. GGE biplot analysis suggested presence of two megalocations and enabled identification of specifically adapted varieties. However, GLI couldn't be exploited from one season experiment and, therefore, farmers in the Zone should grow high seed yielding and broadly adapted varieties.
\end{abstract}

Keywords: AMMI, GGE, Yield stability, GLI, Broad adaptation, Genotype, Environment.

\section{INTRODUCTION}

Common bean (Phaseolus Vulgaris L.) is one of the most important cash crops and source of protein for farmers in many lowlands and mid-altitude zones in Ethiopia (Assefa et al., 2005; Katungi et al., 2010). It is highly preferred by Ethiopian farmers because of its fast maturing characteristics that enable households to get cash income required to purchase food and other household needs when other crops are immature and on the field (Legesse et al., 2006). In recent years, it is becoming important export earnings of the country (Gezahegn and Dawit, 2006). Its export earning is estimated to be over $85 \%$ of export earnings from pulses (Negash, 2007). It ranks third as an export commodity after coffee and sesame and contributes about $9.5 \%$ of total export value from agriculture in the country (FAOSTAT, 2010).

There is general belief that common bean was introduced to Ethiopia in the $16^{\text {th }}$ century by the Portuguese traders (Imiru, 1985). In Ethiopia, it is grown suitably in areas with an altitude ranging between $1200-2200 \mathrm{~m}$ above sea level with optimum temperature range of $16-28^{\circ} \mathrm{C}$ and a rainfall of $350-500 \mathrm{~mm}$ well distributed over the growing season (Liebenberg, 2002; Mekbib, 2003). It performs best on deep, friable and well aerated soil with good drainage, reasonably high nutrient content and $\mathrm{pH}$ range of 5.8 to 6.5 (Liebenberg, 2002).

Both area coverage and production of common bean have been increasing in Ethiopia since 2002 in response to economic reforms of the 1990s (Legesse et al., 2006; Katungi et al., 2010). It had area coverage of $244,012.80$ hectares and production of 3,628,903 quintals in 2010 in Ethiopia (CSA, 2010). However, its average national yield was estimated at $1487 \mathrm{~kg} \mathrm{ha}^{-1}$, which is still low as compared to attainable yield of $2000-3000 \mathrm{~kg} \mathrm{ha}^{-1}$ from improved varieties under good management condition (HARC, 2002; CIAT, 2003; Mekbib, 2003; Emishaw, 2007; Asfaw et al., 2008). Its average yield in the study area is $1231 \mathrm{~kg} \mathrm{ha}^{-1}$ (CSA, 2010), which is again very low compared to the attainable yield indicated earlier. 
Several biotic and abiotic factors are attributed to the low yield of common bean in Ethiopia and in the study area, Dawro Zone, including lack of high seed yielding improved varieties for the different agro-ecological zones, poor cultural practices, moisture stresses, low soil fertility, diseases and insect pests (Mekbib, 2003; Chemeda and Bulti, 2006; Katungi et al., 2010).

In Ethiopia, nationally coordinated breeding of common bean was started in 1970 with a number of new introductions and evaluation at different locations (Amare, 1987). From 1973 to 2010, thirty seven common bean varieties had been developed and released for cultivation from national and regional Agricultural Research Centers (MoARD, 2010). None of these improved varieties had introduced into the study area except, Red Wolaita, which was introduced into the Zone before 30 years. Farmers in the study area had been cultivating landraces for about five centuries and Red wolaita for about 30 years. Red Wolaita is now low seed yielding and poor in quality due to loss of its genetic purity because of mixing up with landraces, genetic drift, and partly due to natural out crossing. Therefore, introduction of high-yielding and well-adapted common bean varieties is required.

When genotypes are introduced into new environments, genotype $\mathrm{x}$ environment interaction (GEI) is expected and in its presence, selection of superior genotypes based on means averaged over locations is misleading (Ebdon and Gauch, 2002b; Gauch and Zobel, 1997). GEl reflects differences in adaptation and can be exploited by selecting for specific adaptation or minimized by selecting for broad adaptation (Adjei et al., 2010). These objectives can be achieved by grouping environments into mega-environments and then selecting specifically adapted genotypes for each mega-environment or broadly adapted genotypes for wider region (Annicchiarico, 2002). Multilocation evaluation of genotypes and stability analysis provides useful information for mega-environment classification and identification of broadly or specifically adapted genotypes (Crossa, 1990).

Several statistical analysis methods have been used for interpretation of GEI. But currently, AMMI and GGE models are preferred tools for multi-location trials data analysis and which genotype outsmart where pattern discovery (Samonte et al., 2005; Gauch Jr., 2006; Yan et al., 2007; Gauch Jr. et al., 2008; Asfaw et al., 2009; Namaratu et al., 2009). In the study area, there is no or little information on Genotype x Environment interaction and adaptability in common bean. As a result, this research was done to estimate the magnitude of variety by environment interaction effects and to analyze the adaptability/stability of varieties for seed yield performance in Dawro zone.

\section{MATERIALS AND METHODS}

The experiment was conducted during the 2010 main cropping season at seven representative locations in the beans growing areas of Dawuro zone. It is located in the southwestern part of Ethiopia $282 \mathrm{~km}$ from Hawassa and $507 \mathrm{~km}$ from Addis Ababa through Wolaita Sodo at $6^{\circ} 52^{\prime} \mathrm{N}$ to $7^{\circ} 13^{\prime} \mathrm{N}$ latitude and $37^{\circ} 07^{\prime} \mathrm{E}$ to $37^{\circ} 26^{\prime} \mathrm{E}$ longitudes. The locations represent varying agro-ecologies of the zone. The characteristics of experimental locations are given in Table 1. Map of the locations was given in Figure 1. Experimental materials were 14 common bean varieties constituting of 13 new introductions to the study area and one check variety. Their code is G1=Gofta, G2=Goberasha, G3=Beshbesh, G4=Zebra-90, G5=Mexican-142, G6=Roba-1, G7=Awashmelka, G8=Tabor, G9=Dimitu, G10=Nasir, G11=Red wolaita, G12=Ibbado, G13=Omo-95, and G14=Hawassa dume. The seeds of test varieties were obtained from Melkassa, Hawassa, and Areka Agricultural Research Centers.

Randomized complete block design (RCBD) with three replications was used in all sites. The plot size was $1.6 \mathrm{~m} \times 4 \mathrm{~m}\left(6.4 \mathrm{~m}^{2}\right)$ with four rows of spacing $40 \mathrm{~cm}$ between rows and $10 \mathrm{~cm}$ between plants. The net harvested area was $3.2 \mathrm{~m}^{2}$, which covered the middle two rows. Two seeds per hill were sown on rows with manual drilling to ensure germination and good stands of the bean varieties and then were thinned to one plant per hill 12 days after emergence to achieve 160 plants per plot. Recommended DAP fertilizer rate of $100 \mathrm{~kg}^{\text {ha- }}{ }^{1}$ was applied to each plot during sowing. Land preparation, sowing and other cultural practices were followed as per recommendations for common bean. 
Table 1. Characteristics of the test locations

\begin{tabular}{|c|c|c|c|c|c|c|c|}
\hline \multirow[b]{2}{*}{ Locations } & \multirow{2}{*}{$\begin{array}{l}\text { Altitude } \\
\text { (m. a.s.l.) }\end{array}$} & \multirow[b]{2}{*}{ Soil texture } & \multirow[b]{2}{*}{ Latitude } & \multirow[b]{2}{*}{ Longitude } & \multicolumn{2}{|c|}{ Temperature $\left({ }^{\circ} \mathrm{C}\right)$} & \multirow{2}{*}{$\begin{array}{l}\text { Rainfall } \\
(\mathrm{mm})\end{array}$} \\
\hline & & & & & Minimum & $\overline{\text { Maximum }}$ & \\
\hline Turi & 1773 & Clay & $7^{\circ} 06169 " \mathrm{~N}$ & $37^{\circ} 11^{\prime} 733 " \mathrm{E}$ & 12.0 & 27.0 & 1645 \\
\hline Tarcha & 1342 & Clay loam & $7^{\circ} 9^{\prime} 210^{\prime \prime} \mathrm{N}$ & $37^{\circ} 10^{\prime} 365^{\prime \prime} \mathrm{E}$ & 16.5 & 32.0 & 1405 \\
\hline Yalo & 1270 & S. clay loam & $6^{\circ} 56^{\prime} 990^{\prime \prime} \mathrm{N}$ & $37^{\circ} 20^{\prime} 551 " \mathrm{E}$ & 15.0 & 28.0 & 1400 \\
\hline Duga & 1760 & S. clay loam & $7^{\circ} 05^{\prime} 180^{\prime \prime} \mathrm{N}$ & $37^{\circ} 20^{\prime} 096 " \mathrm{E}$ & 13.0 & 25.0 & 1700 \\
\hline Wara & 1465 & Clay loam & $7^{\circ} 10^{\prime} 065^{\prime \prime} \mathrm{N}$ & $37^{\circ} 03^{\prime} 783^{\prime \prime} \mathrm{E}$ & 14.0 & 25.0 & 1340 \\
\hline Bero & 1800 & S. clay loam & $7^{\circ} 52^{\prime} 075^{\prime \prime N}$ & $37^{\circ} 08^{\prime} 640 " \mathrm{E}$ & 14.0 & 23.0 & 1560 \\
\hline Gendo & 1860 & Clay & $6^{\circ} 58^{\prime} 760^{\prime \prime} \mathrm{N}$ & $37^{\circ} 22^{\prime} 075^{\prime \prime} \mathrm{E}$ & 14.0 & 26.5 & 1465 \\
\hline
\end{tabular}

m. a.s.l. $=$ Meters above sea level, $\mathrm{mm}=$ Millimeter and S.clay loam $=$ Sandy clay loam.

Seed yield data were collected from the central two rows of the plot and adjusted to $12 \%$ seed moisture using the equation (Hong and Ellis, 1996) $\mathrm{Y}_{\mathrm{adj}}=\left[\left(\frac{100-\mathrm{MC}}{100-12}\right) * \mathrm{Y}\right]$, where: $Y_{a d j}$ was moisture adjusted yield, $\mathrm{Y}$ was unadjusted yield, and $\mathrm{MC}$ was measured moisture content (\%).

The analysis of variance was done using SAS software version 9.2 (SAS institute, 2008) and homogeneity of error variances was tested using Bartlett's Test (Gomez and Gomez, 1984).

AMMI model analysis was done using AGROBASE 20 statistical package (Agrobase 20, 1999). Through this model, GLI was further partitioned into IPCA components and their statistical significance was also tested using Gollob's (1968) F-statistic. The AMMI model ( Zobel et al., 1988) was:

$$
y_{i j}=\mu+g_{i}+e_{j}+\left(\sum_{1}^{n} K_{n} U_{i n} S_{j n}\right)+Q_{i j}+\epsilon_{i j}
$$

Where: $y_{i j}$ is the mean yield across replicates of the $\mathrm{i}^{\text {th }}$ variety in the $\mathrm{j}^{\text {th }}$ environment, $\mu$ is the grand mean, $g_{i}$ is the additive effect of $i^{\text {th }}$ variety, $e_{j}$ is the additive effect of $j^{\text {th }}$ environment, $K_{n}$ is the singular value of the IPCA axis $n$, $U_{i n}$ and $S_{j n}$ are scores of variety $i$ and location $j$ for the IPC axis $n$, respectively, $Q_{i j}$ is the residual for the first $n$ multiplicative components, and $\epsilon_{\mathrm{ij}}$ is the residual error assumed to be normally and independently distributed as $\left(0, \sigma^{2} / \mathrm{r}\right)$ (where $\sigma^{2}$ is the pooled error variance and $r$ is the number of replicates). 


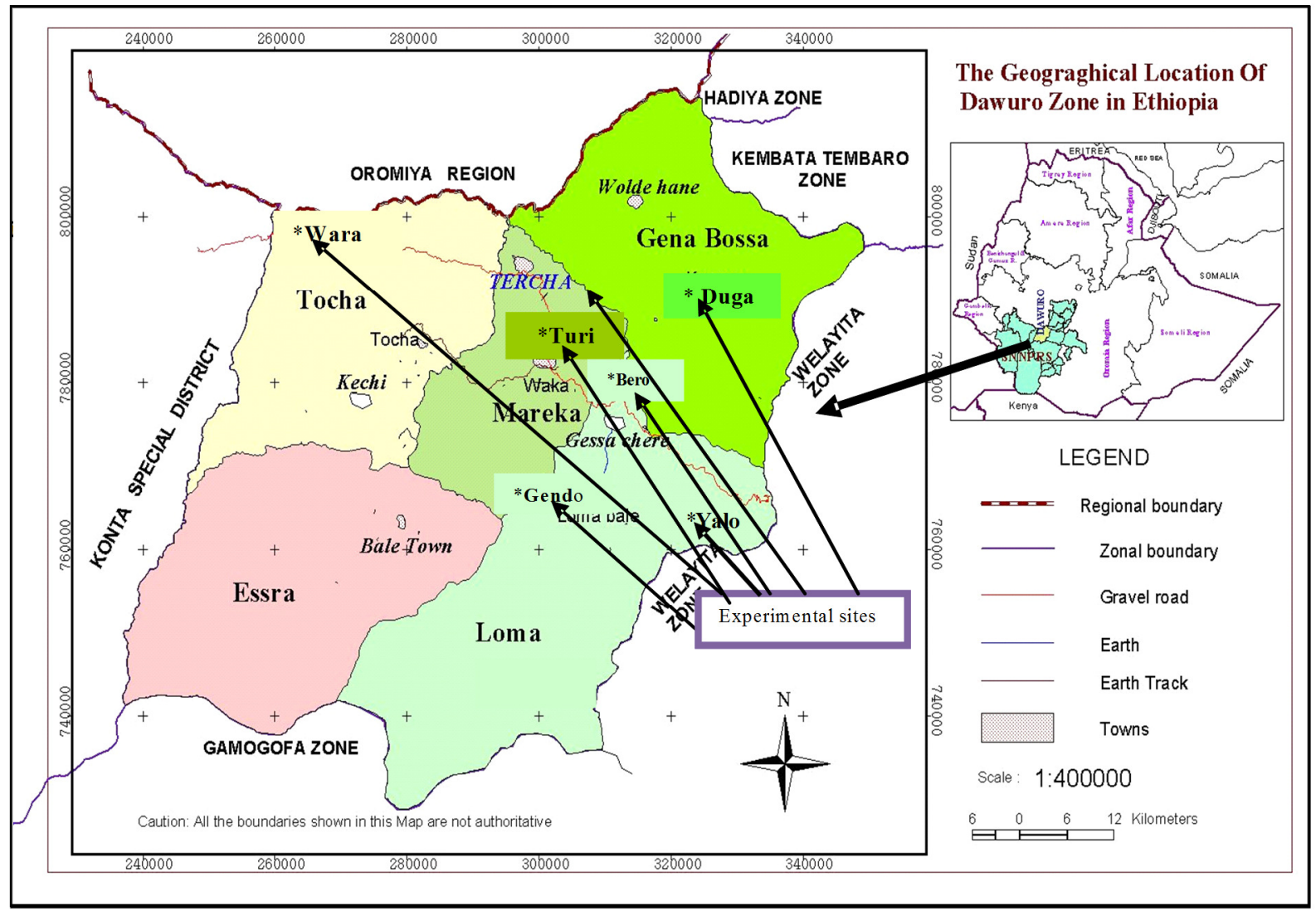

Figure 1. Map of Dawuro zone and the experimental locations Source: SNNPRS Bureau of Finance and Economic Development

To show a clear insight into specific variety by location interaction (GLI) combinations and the general pattern of adaptation biplots of varieties and locations (Kempton, 1984) , GGE were developed using AGROBASE 20 and Genstat version 17 statistical packages. AMMI stability value (ASV), length of variety and environment markers from the origin in a two dimensional plot of IPCA ${ }_{1}$ scores against IPCA ${ }_{2}$ scores, was calculated according to Purchase (2000) as:

$$
\mathrm{ASV}_{\mathrm{i}}=\sqrt{\left[\frac{\left.\mathrm{SS}_{\text {IPCA1}}\left[\mathrm{ISCA}_{\text {IPCA } 2}\right]\right]^{2}+\left[\mathrm{IPCA} 2_{\text {score }}\right]^{2}}{2}\right.}
$$

Where: $\mathrm{SS}_{\mathrm{IPCA}} / \mathrm{SS}_{\mathrm{IPCA} 2}$ is the weight given to the IPCA1 score by dividing the IPCA1 sum of squares by the IPCA2 sum of squares.

Then genotype selection index $\left(\mathrm{GSI}_{\mathrm{i}}\right)$ was also calculated for each variety to identify broadly adapted and high yielding varieties. GSI incorporates adaptability and mean performance. It is the sum of ranks of varieties due to mean performance for the trait across locations and $A M M I$ stability value $\left(\mathrm{ASV}_{\mathrm{i}}\right)$ (Purchase, 2000). 


\section{RESULTS AND DISCUSSION}

\subsection{Variety by Location Interaction Analysis}

\subsubsection{Combined ANOVA model analysis}

The mean squares from the combined analysis of variance over locations are presented in Table 2. The analysis showed that varieties, locations, and GLI effects were highly significant $(p<0.01)$. This indicated the diversity of locations and presence of substantial genetic differences among the varieties for seed yield performance. Mekbib (2003) and Asfaw et al. (2008) reported similar findings in common bean varieties and their growing environments in Ethiopia. The significant GLI also indicated that the relative performance of varieties at different locations was not similar. This was similar with the results reported by other investigators (Mekbib, 2003; Asfaw et al., 2008; Mwale et al., 2008; and Pereirra et al., 2009).

Combined analysis of variance partitions the variation in a two way factorial multi-environment trial data into variety main effects, environment main effects, and variety by environment interaction effects with the most common outcome of largest environment main effects followed by the interaction effects and then the variety main effects (Yan and Kang, 2003; Gauch Jr, 2006). In the present study, the largest effects of location (50.27\%) followed by variety effects $(28.81 \%)$ and then by GLI effects $(20.92 \%)$ were observed. Hence, GLI exerted nearly the same effect as exerted by variety main effect to the observed phenotype and highly significantly complicated selection of superior and adaptable variety. Therefore, simultaneous consideration of both high mean performance (main effects) and GLI (stability) is very important in selecting among the varieties evaluated for these traits performance. This is in agreement with the reports of Mekbib (2003), Asfaw et al. (2008), Mwale et al. (2008), and Pereirra et al. (2009).Combined ANOVA determines if GEI is a significant source of variation or not, but does not provide insight into the patterns of varieties or locations that give rise to the interaction (Samonte et al., 2005). Therefore, the combined data was also analyzed using AMMI model that further partitions GLI into IPCA components.

\subsubsection{AMMI Model Analysis}

The AMMI model analysis of variance for seed yield is presented in Table 2. This analysis also showed presence of highly significant $(p<0.01)$ differences among varieties for seed yield performance. From the total treatment sum of squares, the largest portion was due to location main effect $(50.27 \%)$ followed by variety main effect $(28.81 \%)$ and the effect of GLI was $20.92 \%$. The large portion of location sum of squares indicated greater influence of the location on seed yield performance of common bean varieties and contributed greater to GLI when compared to that of varieties as main effects.

Partitioning of GLI through AMMI model had revealed that all IPCA 1 to IPCA 5 were highly significant $(p<$ $0.01)$ and $I_{P C A}$ was found significant $(p<0.05)$ using an approximate F-statistic (Gollob, 1968) (Table 2). The Gollob's test most often retains the axis with a low proportion of explained GLI (Voltas et al, 2002). Zobel et al. (1988) stated AMMI with the first two IPCA terms is the best predictive model. In this study, the IPCA and IPCA $_{2}$ had explained 39.25 and $29.25 \%$ of GLI sum of squares, respectively and together accounted for nearly $70 \%$ of variation in the GL interaction (Figure 3). Therefore, they best predicted seed yield performance variation explained by GLI by excluding IPCA $\mathrm{IPCA}_{4}, \mathrm{IPCA}_{5}$, and, IPCA $\mathrm{P}_{6}$ which were buried into noise. Thus, the overall pattern of varieties interaction with locations was interpreted using both AMMI1 and AMMI2 models. 
Table 2. Mean squares for the combined ANOVA and AMMI models analysis of variance for seed yield of 14 common bean varieties tested at seven locations in the $\mathbf{2 0 1 0}$ main cropping seasons

\begin{tabular}{lcrr}
\hline & & \multicolumn{2}{c}{ Mean squares } \\
\cline { 2 - 4 } Sources of variation & $\begin{array}{c}\text { Combined } \\
\text { Degree of } \\
\text { freedom }\end{array}$ & $\begin{array}{l}\text { ANOVA } \\
\text { model }\end{array}$ & $\begin{array}{c}\text { AMMI } \\
\text { model }\end{array}$ \\
\hline Location (L) & 6 & $7440445^{* *}$ & $7440542^{* *}$ \\
Reps within location & 14 & $52376.5^{* *}$ & $52376.4^{* *}$ \\
Variety (G) & 13 & $1967821^{* *}$ & $1967706^{* *}$ \\
GLI & 78 & $238166^{* *}$ & $238168^{* *}$ \\
IPCA 1 & 18 & - & $405053.4^{* *}$ \\
IPCA 2 & 16 & - & $346981.4^{* *}$ \\
IPCA 3 & 14 & - & $185956.5^{* *}$ \\
IPCA 4 & 12 & - & $142846^{* *}$ \\
IPCA 5 & 10 & - & $103242.1^{* *}$ \\
IPCA 6 & 8 & 21849 & $48060^{*}$ \\
Error & 182 & & 21849.1 \\
\hline CV (\%) & & 96 & 7 \\
R2 & & 28.81 & 96 \\
\hline \% (G) & & 50.27 & 28.81 \\
\% (L) & & 20.92 & 20.92 \\
\% (GLI) & & & \\
\hline
\end{tabular}

$*{ }^{* *}=$ Significant at 0.05 and 0.01 level of probability, respectively, ns $=$ Non significant at 0.05 probability level. Abbreviations; and GY = Seed yield (kg/ha), CV $=$ Coefficient of variation, and $R^{2}=$ Coefficient of determination .

\subsection{Stabilty Analysis}

\subsubsection{AMMI biplots analysis}

The results of AMMI biplots analysis for seed yield performance of varieties is presnted in Figures 2 and 3 . Figure 2 is AMMI1 biplot and illustrated $87.31 \%$ of treatment sum of squares from which $50.27 \%, 28.81 \%$, and $8.21 \%$ were due to location, variety, and IPCA1 effects respectively (Table 2). In AMMI1 biplot, the varieties with IPCA1 scores close to zero express general adaptation and the larger scores depict more specific adaptation in combination with locations of the same sign IPCA1 scores (Ebdon and Gauch, 2002a). Furthermore, the relative magnitude and direction of varieties along the abscissa and ordinate axis in biplot is also important to understand the response pattern of varieties across locations and to differentiate high yielding and adaptable varieties (Samonte et al., 2005). Accordingly, in Figure 2, G6, G2, G7, G10 and G4 placed relatively close to zero IPCA1 score line and performed above the overall mean were generally adapted to all locations. The high yielding varieties (G13 and G11) have similar sign IPCA1 scores with IPCA1 score sign of Tarcha, Duga, Turi, and Bero showed positive interaction with these locations. Thus, they were specifically adapted to these locations. Similarly, the high yielding varieties (G9, G3, G14, and G12) with similar sign of IPCA1 score to Gendo, Yalo, and Wara showed positive interaction with these locations and specifically adapted to them. G5 located away from all locations was un-adapted to all locations (Fig. 2). Yan et al. (2007) and Kaya et al. (2002) reported similar interpretations.

Considering locations, Yalo, Tarcha and Wara exhibited high seed yield performance (Fig. 2). Thus, they are ideal locations for commercial production of common bean varieties found specifically or widely adapted to them. Duga, Turi, and Bero were low seed yield potential locations. As it is located furthest away from zero line of I P C A 1 
score, Wara showed greatest interaction with varieties followed by Bero and Tarcha. Gendo had medium seed yield potential and relatively less discriminated varieties next to Turi. Therefore, the performance of varieties at locations Turi and Gendo was relatively additive and selection of high yielding varieties based on mean performance could be rewarding at these locations.

Overall, the varieties adaptability ranking for seed yield performance based on lower absolute IPCA1 scores was G6 = Roba 1 (1.4031) > G2 = GobeRasha (2.1926) > G7 = Awashmelka(2.3909) > G10 = Nasir(2.7646) > G4 = Zebra-90(3.6205) > G8 = Tabor(4.7262) > G13 = Omo-95(4.7722) > G1 = Gofta(11.4004) > G11 = Red wolaita(11.5170) > G9 $=\operatorname{Dimitu}(11.5825)>\mathrm{G} 3=\operatorname{Beshbesh}(12.9155)>\mathrm{G} 14=$ Hawassa dume $(13.1936)>\mathrm{G} 12=$ Ibbado(16.2266) > G5 = Mexican 142 (21.9004) (Fig. 2). The locations stability ranking was Turi (1.929) > Gendo (2.085) > Duga (8.218) > Yalo (10.17) > Tarcha (14.04) > Bero (17.61) > Wara (29.54) (Fig. 2 ).

The AMMI1 biplot, Fig. 2, had visualized not only the varieties performance in relation to adaptability and mean seed yield performance, but also revealed presence of two mega-locations. Four locations (Tarcha, Duga, Turi, and Bero) with similar IPCA1 scores had formed one mega-location whereas three locations (Wara, Yalo, and Gendo) had formed another mega-location. However, its mega-environment classification is more general and didn't show detailed specific adaptation of varieties. Therefore, more specific adaptability of varieties was explored using AMMI2 biplot (Fig. 3).

In AMMI2 biplot, the distances from the biplot origin indicates of the amount of interaction exhibited by varieties over environments and vice versa. Varieties located near the biplot origin are less responsive than the vertex varieties indicating general adaptability to all environments (Voltas et al., 2002).

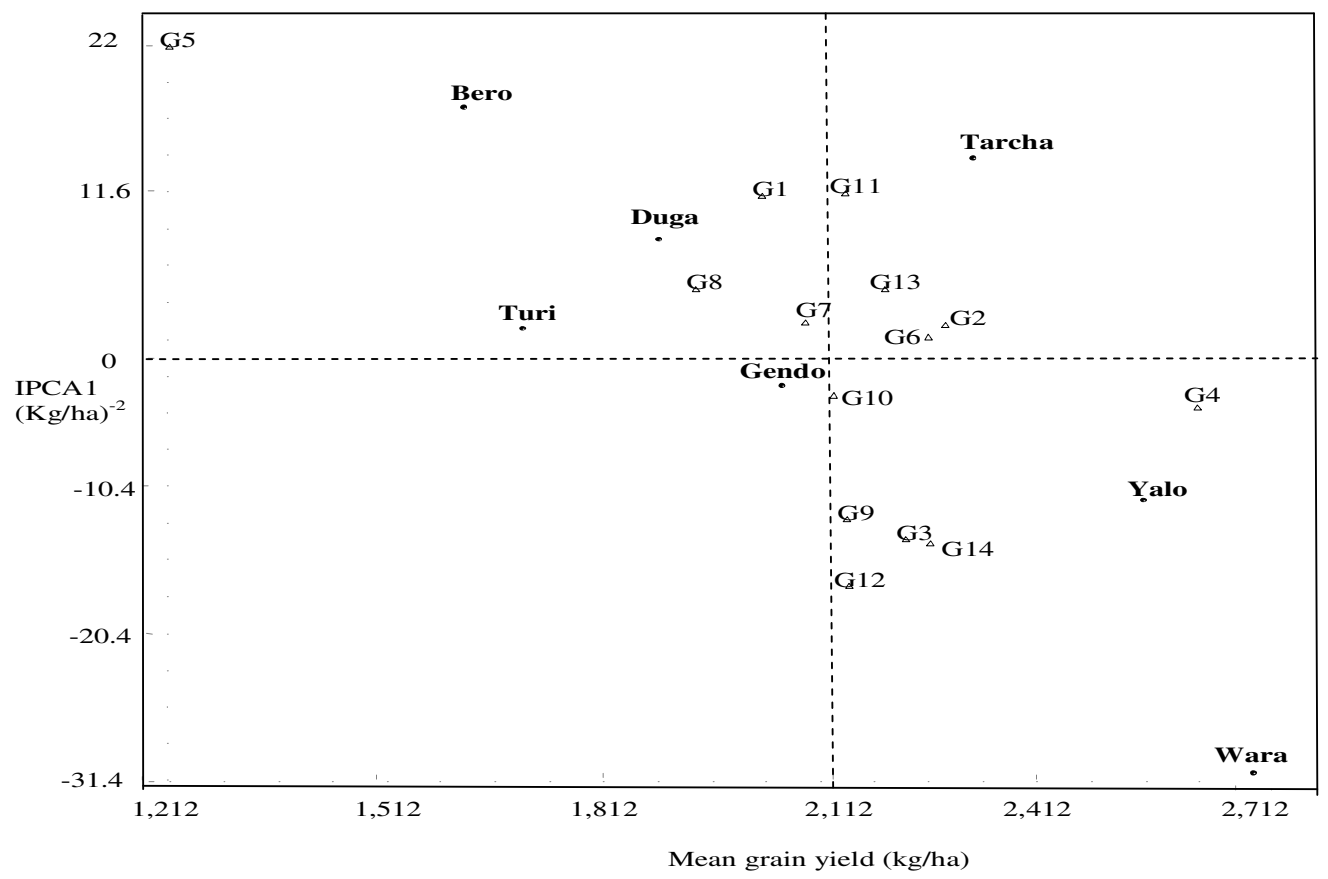

Figure 2. AMMl1 biplot of seed yield. Varieties plotted as G1, G2 ... G14. Locations are those written by sentence case letters and bolded

Locations with longer vectors are very interactive and discriminate the differences among varieties more than locations with shorter vectors. Shorter vectors are less interactive and provide little or no information about the differences among varietal performances (Yan, 2002). Hence, in Figure 3, the varieties (G12, G13, G5, G10, and G3) placed furthest way from the biplot origin expressed a highly interactive behavior (positively or negatively) whereas G7 placed relatively close to the biplot origin expressed less interaction and more adaptable to all locations. Similarly, in the AMM2 biplot, the angles between variety, environment, or between variety and environment vectors determine the nature of GEl. The interaction is positive for acute angles, zero for right angles, and negative for obtuse angles (Kandus et al., 2010). Accordingly, G12, G14, G9, G2, G6 and G13 which make acute angles with Yalo vector showed positive interaction and specifically adapted to this location (Fig. 3 ). G13, G2, G11 make acute angles and interacted highly positively with Duga vector and specifically adapted to it. G1, G13 and G11 interacted highly positively with Bero vector and specifically adapted to it. G11, G4, and G10 have acute angles with Tarcha vector were specifically best varieties for it. G4, G10, G3, G14, and G 9 interacted highly positively with Wara and 
adapted to it. G3, G4, G10 interacted highly positively with Gendo and adapted to it. Turi placed close to the origin and hence showed less interaction with varieties. Therefore, high seed yielding varieties at these locations were best for it. G5 again being placed away from all locations was failed to adapt to all locations.
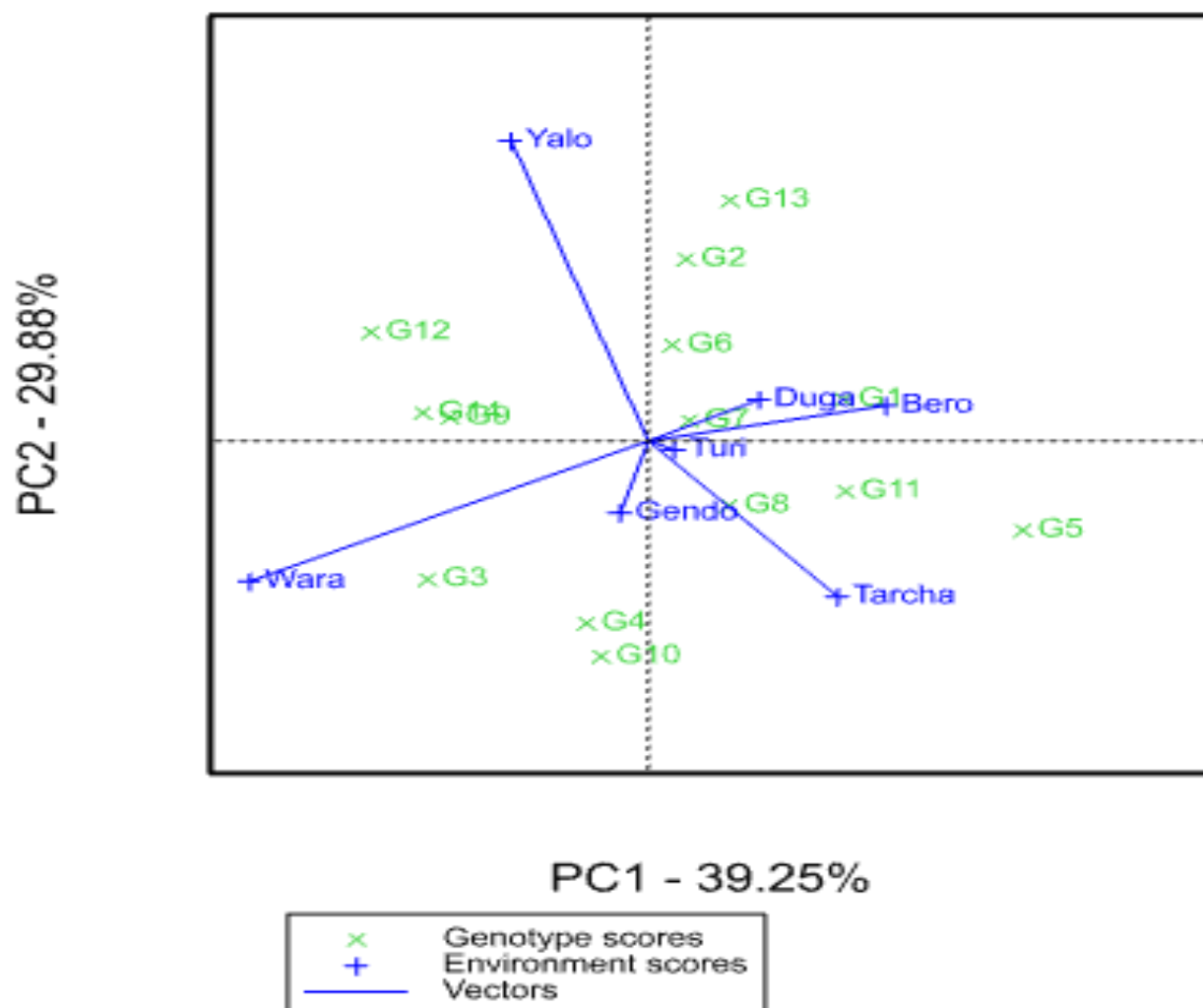

Figure 3. AMMI2 biplot showing specific adaptability of test varieties. Varieties plotted as G1, G2 ... G14. Locations are those written by sentence case letters

\subsubsection{GGE biplot analysis}

Connecting the extreme varieties on a GGE biplot forms a polygon and the perpendicular lines to the sides of the polygon form sectors of varieties and locations (Gauch and Zobel, 1996; Kaya et al., 2002). Thus, in the GGE biplot (Fig. 4), four sectors of which two with locations were observed. Duga, Gendo, Turi, Tarcha, and Wara were clustered in one sector and could be considered as one mega-location for common bean varieties evaluation and recommendation. Their higher yielding varieties were G12, G9, G14, G4, and G3. The other locations namely Yalo and Bero that had entered into one sectors had also formed another mega-location with their higher yielding varieties G13, G2, G6, G1, and G7. But, data from multiple years are needed to declare the presence of mega-locations (Yan et al. 2007).

\subsubsection{AMMI stability value and variety selection index analysis}

AMMI stability value, variety selection index values, and ranks based on them are presented in Table 3 . According to AMMI stability value (ASV), varieties, Awashmelka (G7), Roba-1 (G6), Tabor (G8), Goberasha (G2), and Zebra-90 (G4) were found to be broadly adapted. According to GSI, varieties Roba-1 (G6), Goberasha (G2), Zebra-90 (G4), Awashmelka (G7), Hawassa dume (G14), Dimitu (G9), and Red Wolaita (G11) with relatively lower ranks (first to fifth) were found high seed yielding and broadly adapted varieties (Table 3). AMMl1 biplot identified G6, G2, G7, G10 and G4 as broadly adapted and high seed yielding (Fig. 2). Thus, GSI is nearly similar to AMMI1 biplot in identifying stable varieties. Combining all stability measures, G6, G2, G7 and G4 were selected as high seed yielding and broadly adapted by all AMMI1 biplot, ASV and GSI similarly as reported by Mwale et al. (2008) and Pereirra et al. (2009). However, AMMI1 biplot was the only measure that identified G10 (Nasir), which is now at popular production in the study area, as widely adapted. 


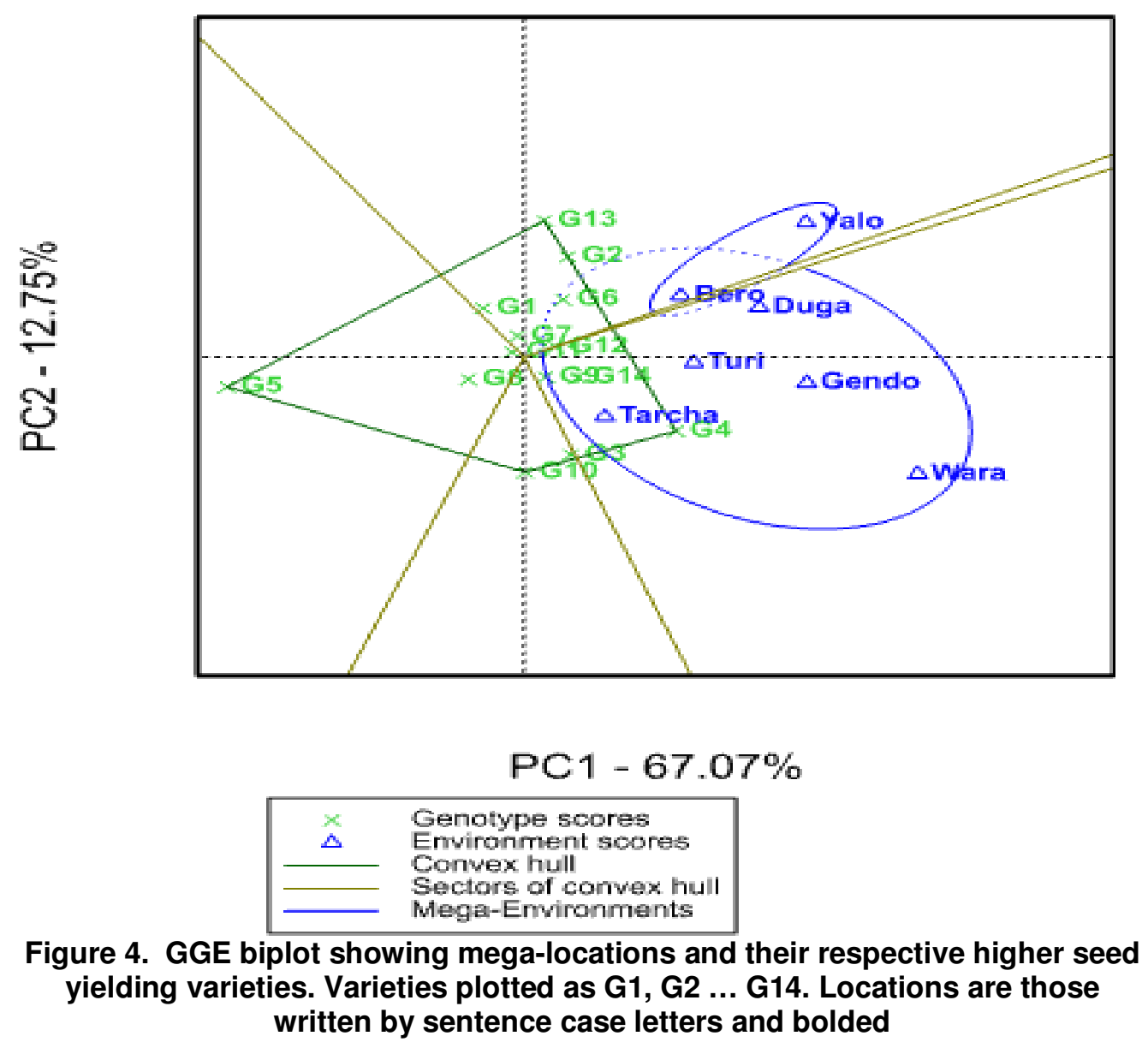

\section{CONCLUSION}

GEI is differential phenotypic performance of genetically uniform genotypes across test environments. It occurs because different genotypes have different genetic potentials to adjust themselves to variable environments, that is, adaptability. Common bean varieties evaluated have highly significant genetic differences for seed yield performance and occurrence of significant GLI complicated selection of high seed yielding and broadly adapted varieties. AMMI 1 biplot enabled identification both high seed yielding and broadly adapted varieties better than ASV and GIS. Similarly, specific adaptability show of GGE biplot is clearer than AMMI2 biplot. Zebra-90, Roba 1, GobeRasha, Awashmelka, Nasir, and Omo-95 are both high seed yielding and broadly adapted varieties. Locations, Yalo, Tarcha and Wara are high seed yield potential locations and ideal for commercial production of common bean varieties broadly adapted to them. GGE biplot analysis suggested presence of two mega-locations and enabled identification of specifically adapted varieties. However, GLI couldn't be exploited from one season experiment and, therefore, farmers in the Zone should grow high seed yielding and broadly adapted varieties. As a result of this recommendation, now the variety, Nasir, which was selected as broadly adapted by AMMI1 biplot is at popular production in the Zone. 
Table 2. AMMI stability value, variety selection index, and ranks based on them for seed yield ( $\mathrm{kg} / \mathrm{ha}$ ) of 14 common bean varieties evaluated at seven locations in the $\mathbf{2 0 1 0}$ main cropping season

\begin{tabular}{lllllll}
\hline Varieties & Seed yield & Rank & ASV & Rank & GSI & Rank \\
\cline { 3 - 7 } Gofta & $2019.7^{\text {ef }}$ & 12 & 15.31 & 6 & 18 & 8 \\
Goberasha & $2274.3^{\text {b }}$ & 2 & 14.31 & 4 & 6 & 1 \\
Beshbesh & $2217.2^{\text {bcd }}$ & 5 & 20.04 & 12 & 17 & 7 \\
Zebra-90 & $2622.3^{\mathrm{a}}$ & 1 & 14.83 & 5 & 6 & 1 \\
Mexican-142 & $1200.8^{\mathrm{g}}$ & 14 & 29.58 & 14 & 28 & 10 \\
Roba-1 & $2249.7^{\text {bc }}$ & 4 & 7.62 & 2 & 6 & 1 \\
Awashmelka & $2080.3^{\text {ef }}$ & 11 & 3.5 & 1 & 12 & 2 \\
Tabor & $1929 \mathrm{f}$ & 13 & 7.96 & 3 & 16 & 6 \\
Dimitu & $2137.7^{\text {bcde }}$ & 7 & 15.32 & 7 & 14 & 4 \\
Nassir & $2118.6^{\text {cde }}$ & 10 & 17.01 & 9 & 19 & 9 \\
Red Wolaita & $2133.8^{\text {bcde }}$ & 8 & 15.62 & 7 & 15 & 5 \\
Ibbado & $2141^{\text {bcde }}$ & 6 & 22.9 & 13 & 19 & 9 \\
Omo-95 & $2190.2^{\text {bcd }}$ & 5 & 19.57 & 11 & 16 & 6 \\
Hawassa dume & $2253.3^{\text {bc }}$ & 3 & 17.46 & 10 & 13 & 3 \\
\hline
\end{tabular}

Means followed by similar letters down columns for variety means' are not significantly different at the 0.05 probability level based on Turkey's Studentized Range (HSD) test.

\section{ACKNOWLEDGEMENT}

The authors thank JUCAVM (Jimma University College of Agriculture and Veterinary Medicine) for financial support and Melkassa, Hawassa, and Areka Agricultural Research Centers for experimental materials provision.

\section{REFERENCES}

Adjei, A.I., S.O. Dapaah and I.K. Dontwi, 2010. Predicting the best genotype from analysis of genotype by environment interaction. European J. Sci. Res., 45(1): 128-135.

Agrobase 20, 1999. Agronomic software, Inc. Canada.

Amare A., 1987. Haricot bean (Phaseolus vulgaris) varieties performance and recommended methods of production. In: IAR proceedings $8^{\text {th }}$ national crop improvement conference 22-26 April 1987. Addis Ababa, Ethiopia.

Annicchiarico, P., 2002. Genotypexenvironment interactions: challenges and opportunities for plant breeding and cultivar recommendations. FAO, Plant Production and Protection Paper 174, FAO, Rome.

Asfaw, A., T. Assefa, B. Amsalu, K. Negash, F. Alemayehu, and F. Grum, 2008. Adaptation and Yield Stability of small Red Bean Elite Lines in Ethiopia. International J. of Plant Breed. and Genet., 2(2): 51-63.

Asfaw, A., F. Alemayehu, F. Grum, and M. Atnaf, 2009. AMMI and SREG GGE biplot analysis for matching varieties in to soybean production environments in Ethiopia. Sci. Res. and Essay vol. 4(11): 1322-1330.

Assefa, T., G. Abebe, C. Fininsa, B. Tesso and A. Al-Tawaha, 2005. Participatory bean breeding with women and small holder farmers in eastern Ethiopia. World J. of Agri. Sci. 1(1): 28-35. 
Central Statistical Agency (CSA), 2010. Agricultural sample survey. Report on area and production of crop (private peasant holdings, meher season). vol.1, CSA, Addis Abeba.

Chemeda Fininsa and Bulti Tesso, 2006. Breeding food legumes for eastern Ethiopia. Pp.124 -130. Food and Forage Legumes of Ethiopia: Progress and Prospects. Proceedings of the Workshop on Food and Forage Legumes. Addis Ababa, Ethiopia, 22 - 26 September 2003.

CIAT. 2003. New bean varieties for Ethiopian farmers. Highlights: CIAT in Africa.No, 3.

Crossa, J., 1990. Statistical analysis of multilocation trials. Advances in Agronomy. 44: 55-85.

Crossa, J., Gauch H.G., R.W. Zobel, 1990. Additive main effects and multiplicative interaction analysis of two international maize cultivar trials. Crop Science. 30: 493-500.

Ebdon, J. S, H.G Gauch, 2002b. Additive main effect and multiplicative interaction analysis of national turfgrass performance trials II: Cultivar recommendations. Crop Sci. 42: 497-506.

Ebdon, J. S,G.H. Gauch, 2002a. Additive main effect and multiplicative interaction analysis of national turfgrass performance trials: I. Interpretation of genotype x environment interaction. Crop Sci. 42: 489-496.

Emishaw, W., 2007. Comparision of the growth, photosynthesis, and transpiration of improved and local varieties of common bean (Phaseolus vulgaris L) at Haramaya. An Msc Thesis presented to the School of Graduate Studies Haromaya University. 89p.

FAOSTAT, 2010. Food and Agriculture Organization. In: Katungi, E., A. Farrow, T. Mutuoki, S. Gebeyehu, D. Karanja, F. Alemayehu, L. Sperling, S. Beebe, J.C. Rubyogo and R. Buruchara, 2010. Improving common bean productivity: An Analysis of socioeconomic factors in Ethiopia and Eastern Kenya. Baseline Report Tropical legumes II. Centro Internacional de Agricultura Tropical - CIAT. Cali, Colombia.

Gauch, H G. and R. W. Zobel, 1988. Predictive and postdictive success of statistical analyses of yield trials. Theor. Applied Genet. 76: 1-10.

Gauch, H. G Jr, P. H. Piepho and P. Annicchiarico, 2008. Statistical analysis of yield trials by AMMI and GGE: further considerations. Crop Sci. 48: 866-889.

Gauch, H. G., 2006. Statistical analysis of yield trials by AMMI and GGE. Crop Sci. 46: 1488-1500.

Gauch, H.G., and R. W. Zobel, 1996. Optimal replication in selection experiments. Crop Sci. 36: 838-843.

Gauch, H.G., and R. W. Zobel, 1997. Identifying mega-environments and targeting genotypes. Crop Sci. 37: 11-326.

Gezahegn, A. and A. Dawit, 2006. Mareketing of pulses in Ethiopia. pp. 346 -351. Food and Forage Legumes of Ethiopia: Progress and Prospects. Proceedings of the Workshop on Food and Forage Legumes, Addis Ababa, Ethiopia, 22 - 26 September 2003.

Gollob, H. F., 1968. A statistical model that combines features of factor analysis and analysis of variance techniques. Psycromet. 33: 73-115.

Gomez., K. A., and A. A Gomez., 1984. Statistical Procedures for Agricultural Research. 2nd ed. John Wiley and Sons Inc., New York.

HARC, 2002. Improved common bean varieties and their production methods. Leaflet unpublished.

Hong, T.D. and R.H. Ellis. 1996. A protocol to determine seed storage behaviour. IPGRI Technical Bulletin No. 1. (J.M.M. Engels and J. Toll, vol. eds.) International Plant Genetic Resources Institute, Rome, Italy.

Imru, A., 1985. Bean production in Ethiopia. pp. 15-38. In: Regional workshop on potential for field beans (Phaseolus vulgaris L.). In West Asia and North Africa Proceedings of a Regional Workshop in Aleppo, Syria, 21-23 May, 1983. Center International de Agricultura Tropical, Cali, Colombia.

Kandus, M., M. D. Almorza, R. Ronceros, J. C. Salerno., 2010. Statistical methods for evaluating the genotype by environment interaction in Maize (Zea mays L.). FYTON ISSN 0031 9457, 79: 39-46.

Katungi, E., A. Farrow, T. Mutuoki, S. Gebeyehu, D. Karanja, F. Alemayehu, L. Sperling, S. Beebe, J.C. Rubyogo and R. Buruchara, 2010. Improving common bean productivity: An Analysis of socioeconomic factors in Ethiopia and Eastern Kenya. Baseline Report Tropical legumes II. Centro Internacional de Agricultura Tropical - CIAT. Cali, Colombia.

Kaya, Y., C. Palta and S. Taner., 2002. Additive main effects and multiplicative interactions analysis of yield performance in bread wheat genotypes across environments. Turk J. of Agri. 26 :275-279.

Kempton, R. A., 1984. The use of biplots in interpreting variety by environment interactions. J. Agri. Sci. 103:123135.

Legesse, D., G. Kumssa, T. Assefa, M. Taha, J. Gobena, T. Alemaw, A. Abebe, Y. Mohhamed and H. Terefe, 2006. Production and Marketing of White Pea Beans in the Rift Valley, Ethiopia. A Sub-Sector Analysis. National Bean Research Program of the Ethiopian Institute of Agricultural Research

Liebenberg, J. A., 2002. Dry bean production. Dry bean production manual compiled by Directorate Agricultural information services Department of Agriculture in cooperation with ARC, Seed Crops Institute, SouthAfrica. (Available athttp://www.ndg.agric.za/publications(Accessed July 2010)

Mekbib, F., 2003. Yield stability in common bean (Phaseolus vulgaris L.) genotypes. Euph. 130: 147-153.

MoARD. 2010. Ministry of Agriculture and Rural Development. Crop Variety Register Issue no. 8. 
Mwale, V. M., J. M. Bokosi, C. M. Masangano, M. B. Kwapata, V. H. Kabambe, and C. Miles, 2008. Yield performance of dwarf bean (Phaseolus vulgaris L.) lines under Researcher Designed Farmer Managed (RDFM) system in three bean agro-ecological zones of Malawi. African J. of Biotech. 7(16): 2847-2853.

Namarato, H., G. V. Miranda, L.V. Souza, L.R.Oliveira, and R.O. Delima, 2009. Comparing biplot multivariate analysis with Eberhart and Rusell method for genotype x environment interaction. Crop Breeding and Applied Biotechnology, 9: 299-307.

Pereira, S.H., L. C. Melo1, L. C. Faria, L.C. Díaz, M. J. Peloso1, Joaquim G. C.Costa, and A. Wendland, 2009. Stability and adaptability of carioca common bean genotypes in states of the central South Region of Brazil. Crop Breeding and Applied Biotechnology, 9: 181-188

Purchase, J.L., H. Hatting and Cs.Vandenventer, 2000. Genotype by environments interaction of wheat in South Africa: stability analysis of yield performance. South Africa J. of plant sci. 17: 101-107.

Samonte, S.O.PB, L.T. Wilson, A. M McClung, J. C. Medley, 2005. Targeting cultivars onto rice growing environments using AMMI and SREG GGE biplot analysis. Crop Sci. 45: 2414-2424.

SAS Institute Inc. 2008. SAS/STAT ${ }^{\circledR} 9.2$ User's Guide. Cary, NC: SAS Institute Inc.

Voltas J, Van E.F, Igartua E, García del Moral L.F, Molina-Cano J.L, Romagosa I. 2002. Genotype by environment interaction and adaptation in barley breeding: Basic concepts and methods of analysis. In Slafer GA, J L. MolinaCano, R. Savin, J L. Araus, I. Romagosa (eds.) Barley Science: Recent Advances from Molecular Biology to Agronomy of Yield and Quality. The Harworth Press Inc., New York, pp. 205-241.

Yan, W. and M. S. Kang, 2003. GGE biplot: Agraphical tool for breeders, Geneticists, and Agronomists. CRC Press. Baco Raton, FL.

Yan, W., 2002. Singular-value partitioning in biplot analysis of multienvironment trial data. Agron. J. 94: 990-996.

Yan, W., M. S. Kang, M. B. Woods, 2007. GGE biplot vs. AMMI analysis of genotype-by-environment data. Crop Sci. 47: 643-653.

Zobel, R. W., J. M. Wright, G. H. Gauch, 1988. Statistical analysis of a yield trial. Agronomy Journal, 80: 388-393.

Cite this Article: Zeleke Ashango, Sentayehu Alamerew (2017). Seed Yield Stability and Genotype $\times$ Environment Interaction in Common Bean (Phaseolus vulgaris L.) Varieties in Dawro Zone, Southwestern Ethiopia. Greener Journal of Plant Breeding and Crop Science, 5(1): 001-012, http://doi.org/10.15580/GJPBCS.2017.1.083016140 